\title{
Progress in understanding variability in cognitive responses to cholinesterase inhibitor treatment
}

\author{
Valory N Pavlik1,2* and Rachelle S Doody' \\ See related research by Wattmo et al., http://alzres.com/content/3/4/23
}

\begin{abstract}
Limitations on the duration of clinical trials, and the constraints of participant selection for such studies, have left many unanswered questions regarding the optimal duration of drug treatment for Alzheimer's disease patients, as well as the subgroups of patients that benefit most. Carefully designed observational studies in naturalistic settings can provide important supplementary information to aid clinical decision-making and patient counseling. A paper by Wattmo and colleagues published recently in Alzheimer's Research \& Therapy has provided important new information on differential responses to cholinesterase inhibitor (ChEl) treatment in specific subgroups of patients over a 3-year follow-up period. All of the participants in their study were started on one of three ChEls after their initial assessment, and periodic assessments of cognitive change and the dosage of ChEls as well as concomitant medications were subsequently recorded. In addition to providing strong evidence of nondifferential effects on cognition of the three ChEls as used in this practice, the study identified clinically significant differences in the responses of specific subgroups of patients to the initiation of ChEl treatment. Of particular interest to clinicians is the finding that older patients and those with worse cognitive functioning at baseline had a better treatment response. The notion that treatment may be futile in the oldest or the most impaired patients was thus not supported by Wattmo and colleagues' cohort. Additional well-designed naturalistic studies of this type are needed to advance our knowledge of the long-term outcomes obtained with different therapeutic agents, and of the covariates that significantly modify responses to Alzheimer's disease treatments.
\end{abstract}

The study by Wattmo and colleagues published recently in Alzheimer's Research \& Therapy is a welcome addition to the literature on predictors of cognitive decline in Alzheimer's disease (AD) [1]. A large number of risk factors for cognitive decline and $\mathrm{AD}$ in the population have been identified and studied in detail [2-6]. In contrast, relatively little is known about factors that affect progression of cognitive and functional decline once the diagnosis of dementia is established. The median survival time after onset of $\mathrm{AD}$ symptoms can be as high as 11 years $[7,8]$, and it is important for both clinical management and caregiver counseling to be able to predict the probable time course of an individual's loss of cognitive and functional abilities. A critical question for clinicians is whether long-term treatment with anti-dementia

*Correspondence: vpavlik@bcm.edu

'Alzheimer's Disease and Memory Disorders Center, 1977 Butler Blvd, Ste E5.101,

Mail Station BCM650, Houston, TX 77030, USA

Full list of author information is available at the end of the article drugs, beyond the intervals documented in clinical trials, is beneficial in altering progression rates. Clinical trials cannot supply this information because of their relatively brief duration compared with the number of years that people actually live with the disease. Naturalistic studies, on the other hand, are limited because they are not randomized with respect to drug use and often suffer from attrition and other biases.

The meticulous study by Wattmo and colleagues is an important contribution to our understanding of factors that affect the cognitive response (Mini-Mental Status Examination and Alzheimer's Assessment Scale cognitive subscale) to initiation and maintenance of cholinesterase inhibitor (ChEI) treatment over 3 years in a large cohort of patients with possible or probable $\mathrm{AD}$ [1]. The main objective of the study was to compare outcomes for the three different ChEIs (donepezil, rivastigmine, and galantamine). In contrast to other observational studies in which an untreated reference group was identified $[9,10]$, this study does not address the issue of whether treatment was helpful compared with no treatment. Outcomes in Wattmo and colleagues' study 
were not dependent upon the particular ChEI. The most interesting findings in this report thus involve interactions between certain background variables (age, gender, education level, and baseline cognitive scores) and the longitudinal outcomes studied. In particular, older men (age 85) with worse baseline Alzheimer's Assessment Scale - cognitive subscale performance showed the greatest improvement in cognitive scores after treatment initiation. Although higher education was associated with better baseline cognitive scores, individuals with higher educational attainment experienced an accelerated rate of cognitive decline over time. The general finding that older individuals and more severe patients had more improvement after initiation of treatment is important, since clinicians and family members may be tempted to view treatment as more futile or less beneficial in these subsets of patients.

Another clinically significant result reported by Wattmo and colleagues is the clear observation of an initial improvement in the responsive subgroups at 6 months, followed by nearly parallel trajectories of decline over the next 30 months. Although cognitive function continues to decline, initiation of ChEI treatment establishes a new, higher, baseline of performance for the individual. This finding adds further evidence to support the persistent use of ChEI treatment over a long time period [10]. The modeling results, and the graphic presentation of these results, also emphasize the point that baseline cognitive scores are highly predictive of cognitive outcomes observed over time. In Wattmo and colleagues' population, even though ChEI treatment initiation produced greater improvement in more severe patients, those improvements, in general, did not lead to better longterm outcomes compared with patients who started out with milder dementia. This finding is consistent with the report by Doody and colleagues that a standardized clinician assessment of the annual rate of Mini-Mental Status Examination decline from onset of symptoms to diagnosis - the pre-progression rate - predicted the subsequent trajectory of cognitive and functional outcomes over as many as 7 years of follow-up [11].

In many societies, educational attainment is strongly correlated with pre-morbid IQ. The construct of cognitive reserve has been elaborated to explain the phenomenon that individuals with high pre-morbid cognitive functioning perform better on cognitive tests after an $\mathrm{AD}$ diagnosis than those with lower pre-morbid functioning. Some studies, including that of Wattmo and colleagues, find that persons with higher educational attainment decline faster after diagnosis than those with lower education $[1,12,13]$. In our own analysis of progression rates, however, higher education was associated with slower decline [14], a result also seen in some other analyses. Furthermore, we found that education was not even a significant predictor of outcomes after accounting for pre-morbid IQ, suggesting that IQ may be a better surrogate for cognitive reserve. Data from the Scottish birth cohort studies indicate that higher IQ measured in childhood, before the individual's ultimate educational status is known, reduces the risk of late-onset dementia [15]. In their discussion, Wattmo and colleagues suggest that the discrepant results for education between their cohort and ours may be attributable to differences in the mean educational level of the participants. Mean education across clinical cohorts varies, as does the relationship among educational attainment, socioeconomic status, and general cognitive ability. This variability argues for the use of pre-morbid IQ instead of education as the predictor of interest. To advance our understanding of how pre-morbid cognitive ability affects the course of cognitive decline in $\mathrm{AD}$, it would be highly desirable for $\mathrm{AD}$ research groups and clinical centers to include a measure of pre-morbid IQ, either with or without education, in their models of progression. This practice would greatly accelerate the development of a consensus regarding the role of cognitive reserve in both response to treatment and the overall rate of decline after diagnosis.

In conclusion, rigorous observational studies - with careful documentation of both the drug exposure of interest and the outcomes following exposure - are a necessary supplement to data generated in clinical trials. We would argue that studies such as this one authored by Wattmo and colleagues are necessary to make informed treatment recommendations for practice guidelines, and to provide accurate prognostic information to patients and their families. We hope Wattmo and colleagues' study will serve as a model for quality naturalistic AD research, with the caveat that pre-morbid IQ should be included whenever possible as a potential explanatory variable.

\section{Abbreviations}

$A D$, Alzheimer's disease; ChEl, cholinesterase inhibitor; IQ, general intellectual ability.

\section{Competing interests}

The authors declare that they have no competing interests.

\section{Author details}

'Alzheimer's Disease and Memory Disorders Center, 1977 Butler Blvd, Ste E5.101, Mail Station BCM650, Houston, TX 77030, USA. ${ }^{2}$ Department of Family and Community Medicine, Baylor College of Medicine, 3701 Kirby Drive, Houston, TX 77098, USA.

Published: 17 October 2011

\section{References}

1. Wattmo C, Wallin AK, Londos E, Minthon L: Predictors of long-term cognitive outcome in Alzheimer's disease. Alzheimers Res Ther 2011, 3:23.

2. Caselli RJ, Dueck AC, Osborne D, Sabbagh MN, Connor DJ, Ahern GL, Baxter LC, Rapcsak SZ, Shi J, Woodruff BK, Locke DE, Snyder CH, Alexander GE, Rademakers R, Reiman EM: Longitudinal modeling of age-related memory 
decline and the APOE $\varepsilon 4$ effect. N Engl J Med 2009, 361:255-263.

3. Laumet G, Chouraki V, Grenier-Boley B, Legry V, Heath S, Zelenika D, Fievet N, Hannequin D, Delepine M, Pasquier F, Hanon O, Brice A, Epelbaum J, Berr C, Dartigues JF, Tzourio C, Campion D, Lathrop M, Bertram L, Amouyel P, Lambert JC: Systematic analysis of candidate genes for Alzheimer's disease in a French, genome-wide association study. J Alzheimers Dis 2010, 20:1181-1188.

4. Launer LJ, Ross GW, Petrovitch H, Masaki K, Foley D, White LR, Havlik RJ: Midlife blood pressure and dementia: the Honolulu-Asia aging study. Neurobiol Aging 2000, 21:49-55.

5. Biessels GJ, Staekenborg S, Brunner E, Brayne C, Scheltens P. Risk of dementia in diabetes mellitus: a systematic review. Lancet Neurol 2006, 5:64-74.

6. Fotenos AF, Mintun MA, Snyder AZ, Morris JC, Buckner RL: Brain volume decline in aging: evidence for a relation between socioeconomic status, preclinical Alzheimer disease, and reserve. Arch Neurol 2008, 65:113-120.

7. Doody R, Pavlik V, Massman P, Kenan M, Yeh S, Powell S, Cooke N, Dyer C, Demirovic J, Waring S, Chan W: Changing patient characteristics and survival experience in an Alzheimer's center patient cohort. Dement Geriatr Cogn Disord 2005, 20:198-208.

8. Heyman A, Peterson B, Fillenbaum G, Pieper C: The consortium to establish a registry for Alzheimer's disease (CERAD). Part XIV: demographic and clinical predictors of survival in patients with Alzheimer's disease. Neurology 1996, 46:656-660.

9. Atri A, Shaughnessy LW, Locascio JJ, Growdon JH: Long-term course and effectiveness of combination therapy in Alzheimer disease. Alzheimer Dis Assoc Disord 2008, 22:209-221.
10. Rountree SD, Chan W, Pavlik VN, Darby EJ, Siddiqui S, Doody RS: Persistent treatment with cholinesterase inhibitors and/or memantine slows clinical progression of Alzheimer disease. Alzheimers Res Ther 2009, 1:7.

11. Doody RS, Pavlik V, Massman P, Rountree S, Darby E, Chan W: Predicting progression of Alzheimer's disease. Alzheimers Res Ther 2010, 2:2.

12. Hall CB, Derby C, LeValley A, Katz MJ, Verghese J, Lipton RB: Education delays accelerated decline on a memory test in persons who develop dementia. Neurology 2007, 69:1657-1664.

13. Stern Y, Albert S, Tang MX, Tsai WY: Rate of memory decline in AD is related to education and occupation: cognitive reserve? Neurology 1999, 53:1942-1947.

14. Pavlik VN, Doody RS, Massman PJ, Chan W: Influence of premorbid IQ and education on progression of Alzheimer's disease. Dement Geriatr Cogn Disord 2006, 22:367-377.

15. Whalley LJ, Starr JM, Athawes R, Hunter D, Pattie A, Deary IJ: Childhood mental ability and dementia. Neurology 2000, 55:1455-1459.

doi:10.1186/alzrt92

Cite this article as: Pavlik VN, Doody RS: Progress in understanding

variability in cognitive responses to cholinesterase inhibitor treatment. Alzheimer's Research \& Therapy 2011, 3:30. 